\title{
Para pensar a Confiança e a Cultura Política na América Latina'
}

\author{
Denise Mercedes Nuñez Nascimento Lopes \\ Fundação Getúlio Vargas - Opinião
}

\section{Resumo}

Este artigo identifica os determinantes de confiança política e sua relação com o apoio ao regime nos países latino-americanos de tradição democrática relativamente recente.

A partir dos dados do Latinobarômetro de 1996, a autora analisa hipóteses explicativas em uma amostra de cinco países: Argentina, Brasil, Costa Rica, Colômbia e Chile. Os resultados apontam como principais determinantes da confiança nas instituições políticas: a preferência pela democracia em oposição ao autoritarismo, as visões sobre a economia e satisfação com o governo, o otimismo em relação ao futuro do país e do núcleo familiar e o interesse pela política.

Palavras-chave: cultura política, confiança política, democracia, América Latina.

\section{Abstract}

This article identifies the determinants of political trust and its relationship with the support for regime in the relatively recent Latin American democracies.

Based on the 1996 Latinobarometer data, the author analyses five hypothesis about political trust in five countries: Argentina, Brasil, Costa Rica, Colômbia and Chile. The results show that the preference for democracy, the conceptions about economy and satisfaction with the government, the optimism with the country and family futures, and the interest in politics are the main determinants of trust in political institutions.

Keywords: political culture, political trust, democracy, Latin American.

\footnotetext{
${ }^{1}$ Este artigo é baseado na minha dissertação de mestrado aprovada no luperj em setembro de 2003 como requisito parcial para a obtenção do grau de mestre em Ciência Política.
} 
O intuito de estudar a confiança e a cultura política dos cidadãos de países da América Latina insere-se no âmbito mais geral da discussão do papel da confiança na sociedade. As mudanças políticas e sociais mundiais ocorridas nos últimos trinta anos trouxeram novamente para a agenda de pesquisas das ciências sociais o interesse pela cultura política e seu papel na mudança social. Temas como o declínio da confiança nas instituições políticas dos países trilaterais, o processo de redemocratização nos países que saíram do socialismo e a importância da cultura cívica para a democracia, dentre outros, vêm ganhando cada vez mais espaço tanto no meio acadêmico quanto fora dele.

O papel da confiança na sociedade é um dos tópicos deste debate, renovado a partir dos estudos de Robert Putnam (1996) e Ronald Inglehart (1988). O primeiro destacou a existência de confiança interpessoal e do capital social como base para o sucesso democrático. O segundo afirmou que há uma relação direta entre a estabilidade democrática e o enraizamento de valores políticos e de confiança interpessoal. Além disso, a longa tradição de estudos que envolvem a questão das conseqüências da confiança, ou da falta dela, para o sistema político teve seu horizonte de análise ampliado com a difusão dos surveys de atitudes e valores, tanto nos países de tradição democrática quanto naqueles de democratização mais recente.

Um outro ponto, não menos relevante, diz respeito à interseção da problemática da confiança com a discussão sobre a importância da existência de valores democráticos para o fortalecimento do sistema democrático como um todo. Neste sentido, importa perguntar que relação existe entre a confiabilidade do sistema político ou do governo e o enraizamento de valores e princípios democráticos.

Uma grande parte dos cientistas sociais contemporâneos vê a crença na "democracia como o melhor tipo de regime" como um elemento fundamental para a sua própria existência e permanência no tempo. Se, no sistema democrático, as políticas devem se basear na busca do consenso, ao menos entre a maioria, o patamar de confiança e de apoio político expresso pelos cidadãos tem implicações normativas importantes. Assim, a despeito da possibilidade do conflito ou desacordo, também constitutivos do sistema democrático, existe a necessidade de um respeito fundamental pelo regime para assegurar sua estabilidade.

Segundo a literatura especializada, a diminuição no apoio ao regime pode ameaçar sua estabilidade e diminuir a aceitação voluntária dos cidadãos para com a política governamental, enquanto o impacto do apoio às autoridades está confinado ao domínio da atividade eleitoral convencional.

Além do declínio da confiança, verificam-se alterações significativas no comportamento das pessoas frente aos mecanismos tradicionais da democracia representativa, tais como os partidos e as eleições. Neste sentido, os resultados de 
pesquisas recentes são preocupantes ao mostrarem o declínio da identificação partidária e da capacidade de mobilização dos partidos, a redução na taxa de comparecimento às eleições e o decréscimo do interesse pela política nos Estados Unidos e na Europa² (DALTON \& WATTEMBERG, 2000).

Diante das evidências, não existe dúvida de que a relação entre o público e as instituições democráticas alterou-se nas últimas décadas. Um dos pontos debatidos pela literatura internacional contemporânea diz respeito às possíveis conseqüências do declínio das taxas de confiança nas instituições políticas para o funcionamento da democracia nestes países (PHARR \& PUTNAM, 2000). Enquanto para alguns analistas a insatisfação com o desempenho do regime implica em uma redução da solidariedade social, para outros, a confiança nas instituições ainda é elevada e suas oscilações não indicam a possibilidade de uma crise democrática ou social (HUNTINGTON, 2000). Neste artigo, apresento alguns resultados de análise de confiança nas instituições políticas em cinco países latino-americanos, a saber, Argentina, Brasil, Chile, Colômbia e Costa Rica.

\section{Confiança e Democracia na América Latina}

A produção de surveys nacionais que tratam de questões de cultura política, valores e atitudes é de origem recente. Para os países da América Latina, não existem séries de dados de períodos mais amplos para testar com propriedade a influência mútua entre participação e confiança e a distribuição da confiança ao longo do tempo.

Como exemplos destacados, estudos recentes conduzidos na América Central por Booth e Richard (1998), procuram superar a carência de um olhar mais específico sobre a América Latina. Estes pesquisadores procuram ir além de uma visão simplista sobre a participação e a democracia, na medida em que estudam diversas formas de participação e sua relação com atitudes políticas e com a confiança.

Booth e Richard, bem como outros autores, chamam a atenção para o quanto fatores como a repressão, o desenvolvimento constitucional, o corporativismo e os esforços de mobilização do Estado afetam a ação da sociedade civil na América Latina (LINCH, 1997; OLVERA, 1997). Neste estudo, educação e nível de vida provaram ser os fatores que mais influenciam as relações verificadas entre comunalismo e normas democráticas. Os cidadãos mais pobres e menos educados, que são os mais ativos participantes de grupos comunitários, demonstram pouco comprometimento com as liberdades democráticas

\footnotetext{
2 Aqui são apresentados os resultados de investigação sobre o eleitorado e seu comportamento, que analisou dados dos anos 50 aos 90 dos países de democracia avançada.
} 
comparados aos cidadãos mais prósperos e mais educados. Os autores acreditam que o ativismo comunitário, sendo mais forte nos países da América Central com intensa repressão, pode gerar um tipo de sociedade civil confrontacional ou mesmo uma sociedade civil antidemocrática ou alienada.

Estes estudiosos avaliaram também a relação entre capital social, capital político e democracia. Utilizando a escala de democracia de Vanhanen para definir os países mais e menos democráticos, testam o poder explicativo de cada uma das variáveis utilizadas. Os resultados evidenciam que o ativismo de grupos formais se correlaciona positivamente com a democracia, enquanto o ativismo em grupos comunais influencia a direção oposta. Os países com maiores índices de atividade comunal estão no grupo menos democrático (Guatemala e El Salvador) e de nível intermediário (Nicarágua). Esses países experimentaram guerras civis fortíssimas, agravadas pela pobreza, que ajudaram a criar essa estrutura comunal ao lado da forte repressão, inibidora da participação em grupos formais.

Uma vez que, na América Central, o ativismo comunal não contribui para a democracia mensurada ao nível de sistema, os autores acreditam ter mostrado que as atitudes de civilidade que mais diretamente impactam o Estado são aquelas com uma referência ou um impacto político explícito, e não quaisquer atitudes "cívicas".

Outra importante contribuição deste estudo foi mostrar a relação entre o Estado e a promoção ou não de organização social ativa. Análises ulteriores mostraram que a repressão afeta o ativismo social, os vários tipos de participação política e o apoio às normas democráticas. Assim, a seqüência causal aparece como interacional e não linear.

De modo semelhante, Marta Lagos, dedicando-se à relação entre a confiança e democracia na América Latina, apresenta dados, em trabalho recente, dados que evidenciam a conformação de uma cultura política na América Latina baseada na desconfiança e na aparência. Utilizando dados do Latinobarômetro-1996, a autora mostra as baixas taxas de confiança em todos os países da América Latina e o contraste com os países centrais. De acordo com sua pesquisa, a origem histórica colonial comum destes países e a prevalência da pobreza e do autoritarismo nos últimos séculos, resultaram em um conjunto de atitudes e visões que podem ser resumidas na imagem de uma máscara sorridente (LAGOS, 2000).

No centro do espírito latino-americano e da cultura cívica e política da região estaria a atitude de permanecer em silêncio com relação a seus sentimentos e percepções verdadeiros e, assim, manter as aparências. Silêncio e aparência, gêmeos da desconfiança, são as tendências comuns que embasam atitudes e valores na região, forjadas pelos latino-americanos como forma de sobrevivência em meio a este legado histórico. A própria democracia, em muitos países da região, pode ser apreendida pela imagem da máscara sorridente, visto que ela sobrevive 
através de silêncios e aparências, silêncio com relação às violações democráticas e aparência com relação à verdadeira natureza dos regimes democráticos.

Grandes têm sido os problemas políticos, econômicos e sociais que estas democracias vêm enfrentando em seu processo de consolidação e Lagos chama atenção para o quanto a cultura política pode favorecer ou não este processo. É necessário levar em conta que esta cultura política comum de desconfiança e medo na região pode ser problemática para a consolidação da democracia. Neste sentido, a autora constata que há um déficit de confiança interpessoal na região (média entre os 17 países é de 20\% de pessoas que confiam nas demais). Para Lagos, esta ausência de confiança interpessoal é o cerne do problema da baixa confiança nas instituições ${ }^{3}$.

Uma comparação com os países desenvolvidos mostra o grau alarmante do estado das taxas de confiança na América Latina. Segundo dados do World Values Survey de 1990, a confiança interpessoal em países como a Suécia é de 60\% (LAGOS, 2000, p. 4). Foi através de análise destes tipos de dados que Ronald Inglehart, em seu estudo de 1989, concluiu que a confiança se correlaciona positivamente com o produto interno bruto e com a democracia. Para este pesquisador, um país onde as pessoas expressam um alto nível de confiança interpessoal tem mais probabilidades de ser democrático e apresentar um PIB alto. No entanto, é possível questionar se o alto grau de confiança interpessoal provoca ou é provocado pela existência de uma democracia mais consolidada e uma situação econômica estável.

É importante observar que esta questão foi testada por Muller e Seligson (1994), que concluem que não é possível determinar a direção da relação a priori, sendo, no caso latino-americano, a confiança interpessoal baixa pelo déficit democrático e não o contrário. A linha defendida por estes autores é a de que o regime democrático influencia mais as atitudes e os valores políticos dos cidadãos do que o contrário.

Rennó (2001), utilizando os mesmos dados, realiza uma análise mais profunda sobre a confiança interpessoal, a confiança política e a democracia na América Latina. Para este autor, interessa saber, principalmente, quais são os tipos de comportamento político mais fortemente afetados pela confiança interpessoal e em que países essa confiança se correlaciona com mais freqüência com outras medidas de comportamento político. Além disso, devem ser questionadas quais variáveis estimulam a confiança interpessoal.

Em última instância entram em questão aqui alguns dos principais pontos do debate atual sobre a confiança: em que medida a confiança interpessoal é importante como elemento definidor do comportamento político? Por que alguns

\footnotetext{
${ }^{3}$ Lagos não realiza nenhum teste estatístico para avaliar esta hipótese.
} 
indivíduos mostram níveis mais altos de confiança do que outros? Quais são os componentes que influenciam a confiança em nível individual?

Rennó salienta a importância do tema da cultura política no estado atual de estudos sobre a sociedade. A cultura é vista como um comportamento influente, inibindo ou estimulando o envolvimento em questões públicas e a participação nos movimentos e organizações políticas.

Em um dos primeiros testes realizados, o autor verifica que a relação entre confiança e participação não é estatisticamente significativa na maioria dos casos e, quando é significativa, comporta-se de maneira oposta à esperada, ou seja, quando há mais confiança mútua, há menos necessidade de participar em associações cívicas ${ }^{4}$.

Em outro teste, Rennó observa a influência da confiança na participação em questões públicas por ser mais abrangente que a participação formal em associações. Um resultado interessante é o que mostra que tentar convencer os outros de suas idéias políticas e trabalhar em um partido político estão correlacionadas com a confiança de forma positiva em $40 \%$ dos casos. Rennó analisa igualmente a influência da confiança interpessoal para a confiança nas instituições (estão incluídas aqui: o governo, o congresso, os sindicatos e a polícia), e para a confiança nos dirigentes políticos, e descobre uma relação positiva entre elas na maioria dos países da América Latina. Com relação às variáveis que se correlacionam positivamente com a confiança interpessoal, Rennó mostra que importam o otimismo com relação ao futuro, as visões positivas com relação ao funcionamento do regime democrático, a igualdade legal dos cidadãos e a visão sobre a eficiência dos servidores públicos.

O autor salienta ainda que a existência de um regime plenamente democrático cria um ambiente que favorece a emergência de confiança mútua e interação entre os indivíduos. Neste sentido, seu trabalho segue a linha defendida por Seligson e Muller de que o regime democrático influencia mais as atitudes e os valores políticos dos cidadãos do que o contrário.

Um resultado importante do trabalho destes pesquisadores é o de evidenciar que se a confiança é determinante em certos contextos, pode não ser em outros, nos quais questões como a repressão, o conformismo ou outros aspectos podem afetar mais o comportamento dos cidadãos. Dos estudos que até agora têm sido realizados nos países latino-americanos, o que se depreende é que a realidade política e a ação do Estado são fundamentais para o resultado da confiança.

\footnotetext{
4 Aqui foram consideradas: participação em sindicatos, associações voluntárias e partidos políticos. É importante salientar que no caso estudado por Booth e Richard as relações verificadas foram muito baixas.
} 


\section{Os Dados Analisados}

Neste trabalho, utilizamos os dados do Latinobarômetro, survey anual baseado em amostras por cotas de idade e gênero das populações urbanas de 17 países latino-americanos e da Espanha. O tamanho da amostra em cada país varia de 517 a 1.200 entrevistados. Esta pesquisa está limitada aos dados de 1996, quando o número de entrevistados de todos os países foi de $18.516^{5}$.

Os países selecionados correspondem a tipos distintos da região, possuindo semelhanças e diferenças importantes. Esta delimitação resultou, sobretudo, da adoção de dois critérios reguladores desta pesquisa, a saber, permitir que a diversidade latino-americana estivesse representada e, paralelamente, incluir países-chave da região. O Brasil é o país que tem a maior extensão territorial e a maior economia, a Argentina e o Chile também são potências econômicas na região, ainda que em menor grau, e a Colômbia é o país que vive a maior crise social devido ao narcotráfico e aos grupos paramilitares, o que define sua singular importância para o estudo.

Com este cenário, a tarefa seguinte foi identificar os fatores que se correlacionam com a confiança nas instituições políticas dos cinco países selecionados, tentando encontrar as causas do baixo nível de expectativa nas instituições.

Por várias razões, a interpretação de evidências em matéria de opinião pública é problemática. Há que se levar em conta tanto a representatividade da amostra e do período escolhido como a formulação dos questionários e os modelos de análise estatística possíveis de serem utilizados.

Os dados do Latinobarômetro nos dão pistas importantes para entender a cultura política da região. Contudo, sabemos que ainda existe todo um caminho a ser percorrido no sentido de mensurar com maior propriedade a opinião pública destes países. O fato de o Latinobarômetro não utilizar amostras probabilísticas nacionais (exceto as da América Central) e seguir o padrão de perguntas original do Eurobarômetro permite questionar a validade das mensurações obtidas. Por outro

\footnotetext{
${ }^{5}$ A razão principal dessa limitação é que os dados do Latinobarômetro não são públicos e os altos custos da sua obtenção impedem que se realize um trabalho com maior quantidade de dados.

As amostras são diferentes, pois cada país teve uma certa liberdade de adaptar a proposta à sua realidade específica. A cobertura varia de $30 \%$ a $100 \%$ do território nacional - o que acontece apenas nos países da América Central. Em muitos países a amostra é apenas da população urbana, o que limita a possibilidade de inferências sobre o conjunto da população do país.

Nesta investigação, é utilizada uma amostra composta por informações de cinco países: Argentina, Brasil, Chile, Colômbia e Costa Rica, abrangendo um total de 5.600 entrevistados. Destes, 1.196 são argentinos, 1.001 são brasileiros, 1.200 são chilenos, 1.200 são colombianos e 1.007 são costarriquenhos.
} 
lado, é graças a esta estrutura que as comparações podem avançar para outros países, sem esquecer a análise da realidade latino-americana.

Assim, mesmo entendendo que as generalizações e comparações em nível nacional são estritamente sujeitas aos limites apontados, esta tentativa de medir os valores e atitudes dos cidadãos latino-americanos é válida, na medida em que pode nos trazer importantes questões de pesquisa. Conscientes destes limites, assumimos que podem ser tomados como uma descrição operacional da realidade, o que pode indicar não só o padrão de relações existentes na mesma, mas também a direção para futuras pesquisas nesta área.

\section{Os Métodos Elaborados}

Para análise dos dados de confiança, optamos por utilizar um índice somatório da confiança na Presidência da República, no Congresso Nacional e nos partidos políticos, denominado de índice de confiança nas instituições políticas ${ }^{6}$. 0 Alpha deste índice é de 0,76. A Tabela 1 apresenta as correlações gamma entre os componentes do índice:

Tabela 1

Correlações (gamma) entre confiança na presidência, no congresso e nos partidos

\begin{tabular}{|c|c|c|c|}
\hline & $\begin{array}{c}\text { Confiança na } \\
\text { Presidência }\end{array}$ & $\begin{array}{c}\text { Confiança no } \\
\text { Congresso }\end{array}$ & $\begin{array}{c}\text { Confiança nos } \\
\text { partidos }\end{array}$ \\
\hline Confiança na Presidência & - & $0,64^{*}$ & $0,53^{*}$ \\
\hline Confiança no Congresso & - & - & $0,69^{*}$ \\
\hline
\end{tabular}

* Nível de significância de 0,01

Fonte: Latinobarômetro 1996.

\footnotetext{
${ }^{6}$ Para cada uma destas instituições, os entrevistados declararam se tinham muita confiança (1), alguma confiança (2), pouca confiança (3) ou nenhuma confiança (4). As variáveis originais foram recodificadas em 0 - nenhuma, 1 - pouca, 2 - alguma e 3 - muita confiança. As respostas dos três itens foram, então, somadas, excluindo da análise apenas aqueles que não responderam a todos os três itens. Assim, obteve-se uma gradação entre 0 e 9 pontos. A partir daí, optou-se por diferenciar os indivíduos em cinco níveis: confiança política muito baixa (escores 0 e 1), baixa (escores 2 e 3, ou seja, a pessoa confia pouco ao menos em duas das instituições ou nas três), média (escores 4 e 5, confia algo em pelo menos uma e pouco nas outras duas ou algo em duas e pouco em uma), alta (escores 6 e 7, ou seja, confia algo em pelo menos duas, muito em outra ou algo nas três) e os com muito alta confiança nas instituições políticas (escores 8 e 9, ou seja, responderam que confiam muito em pelo menos duas das alternativas ou nas três). Os dados do índice para cada país estão no anexo, Tabela $1 \mathrm{~d}$.
} 
Com relação à confiança que os cidadãos depositam no Presidente da República, observa-se a disparidade entre os países: na Argentina, 46,5\% das pessoas responderam que não têm nenhuma confiança no presidente; no outro extremo, o Chile destaca-se como o país com maior percentual de confiança: $20,8 \%$, seguido do Brasil com $14 \%$ de pessoas que confiam muito no presidente. Com relação à confiança no Congresso, também o Chile detém os maiores percentuais: $12,7 \%$ das pessoas afirmam que têm muita confiança no Congresso e 41,9\% têm alguma confiança (ver Tabelas 1a e 1b, anexo).

Quanto à confiança nos partidos, percebe-se um predominante descrédito desta instituição tradicional da democracia representativa moderna. No Brasil, $42,9 \%$ dos entrevistados afirmaram não ter nenhuma confiança nos partidos. Se somarmos para os cinco países os itens "nenhuma" e "pouca confiança", temos aproximadamente, $70 \%$ dos argentinos, $82 \%$ dos brasileiros, $70 \%$ dos colombianos, $73 \%$ dos costarriquenhos e $65 \%$ dos chilenos com pouca ou nenhuma confiança nos partidos políticos (Tabela 1c, anexo).

Com relação ao apoio ao sistema democrático, utilizamos as seguintes variáveis: apoio à democracia, grau de satisfação com o funcionamento da democracia e variáveis que perguntam sobre a importância dos partidos e do Congresso para a democracia. Os percentuais relativos aos cinco países estudados quanto à preferência pelo sistema democrático estão na Tabela 2:

Tabela 2

Preferência por tipo de regime para Argentina, Brasil, Colômbia, Costa Rica e Chile (\%)

\begin{tabular}{|c|c|c|c|}
\hline & $\begin{array}{c}\text { A democracia é preferível à outra } \\
\text { forma de governo }\end{array}$ & $\begin{array}{c}\text { Tanto } \\
\text { faz }\end{array}$ & $\begin{array}{c}\text { Em certas ocasiões é melhor um } \\
\text { governo autoritário }\end{array}$ \\
\hline Argentina & 76,6 & 8,2 & 15,2 \\
\hline Brasil & 55,9 & 22,6 & 21,5 \\
\hline Colombia & 70,8 & 13,4 & 15,8 \\
\hline Costa Rica & 84,6 & 6,2 & 9,2 \\
\hline Chile & 62,5 & 21,0 & 16,4 \\
\hline
\end{tabular}

Fonte: Latinobarômetro 1996.

Os dados mostram o alto apoio que o sistema democrático recebe em todos os países. Para os casos do Brasil e do Chile, a porcentagem de respostas indiferentes ("tanto faz um regime democrático como um não-democrático") é bem alta se comparada aos demais países e sugere uma certa insatisfação, portanto, com a política formal. 
A satisfação com o funcionamento da democracia no país está aqui entendida como um indicador do desempenho do regime democrático. Se, por um lado, a preferência pela democracia é alta, como se vê na Tabela 2, por outro há um grau de insatisfação muito grande com a forma como essa democracia funciona. 0 caso brasileiro é o mais sombrio, com quase $80 \%$ das pessoas insatisfeitas ou pouco satisfeitas com o funcionamento da democracia e apenas $56 \%$ preferindo o sistema democrático. Junto a essa visão sobre a performance do governo são utilizadas também variáveis sobre avaliação da economia do país e classificação da situação política e econômica nacional.

No Latinobarômetro, há outras duas perguntas com relação à percepção da importância das instituições democráticas: "Pode haver democracia sem Congresso Nacional?", e "A democracia pode funcionar sem partidos?". Para as duas, a resposta é binária no sentido da afirmação ou negação da frase. A distribuição delas é condizente com a da preferência pela democracia.

Tanto a possibilidade da democracia funcionar sem Congresso Nacional quanto a possibilidade deste regime funcionar sem partidos políticos são postas em questão pelos cidadãos, o que demonstra seu conhecimento da importância das "regras do jogo" democrático. O que se afirma aqui é que são fundamentais para a democracia a existência de partidos e a possibilidade de oposição e a existência de um poder paralelo ao poder executivo, o Congresso Nacional. O caso brasileiro, novamente, é o mais preocupante, havendo $42 \%$ de indiferença em relação ao congresso e $43 \%$ em relação aos partidos (Tabelas 3, 4 e 5).

Tabela 3

Possibilidade da democracia sem Partidos Políticos, por País (\%)

\begin{tabular}{|c|c|c|}
\hline & Pode haver democracia sem partidos & $\begin{array}{c}\text { Não pode haver democracia sem } \\
\text { partidos políticos }\end{array}$ \\
\hline Argentina & 18,9 & 81,1 \\
\hline Brasil & 43,0 & 57,0 \\
\hline Colômbia & 44,5 & 55,5 \\
\hline Costa Rica & 14,3 & 85,7 \\
\hline Chile & 30,0 & 70,0 \\
\hline
\end{tabular}

Fonte: Latinobarômetro 1996. 
Tabela 4

Possibilidade da Democracia sem Congresso Nacional, por País (\%)

\begin{tabular}{|c|c|c|}
\hline & Pode haver democracia sem Congresso & $\begin{array}{c}\text { Não pode haver democracia sem } \\
\text { Congresso }\end{array}$ \\
\hline Argentina & 19,2 & 80,8 \\
\hline Brasil & 42,2 & 57,8 \\
\hline Colômbia & 37,8 & 62,2 \\
\hline Costa Rica & 15,3 & 84,7 \\
\hline Chile & 21,4 & 78,6 \\
\hline
\end{tabular}

Fonte: Latinobarômetro 1996.

Tabela 5

Satisfação com funcionamento da Democracia, por País (\%)

\begin{tabular}{|c|c|c|c|c|}
\hline & Nada satisfeito & Pouco satisfeito & Satisfeito & Muito satisfeito \\
\hline Argentina & 18,4 & 39,5 & 34,0 & 8,0 \\
\hline Brasil & 36,6 & 38,9 & 23,7 & 0,7 \\
\hline Colômbia & 20,1 & 43,9 & 27,3 & 8,7 \\
\hline Costa Rica & 5,4 & 25,5 & 37,3 & 31,8 \\
\hline Chile & 15,7 & 46,4 & 31,8 & 6,1 \\
\hline
\end{tabular}

Fonte: Latinobarômetro 1996.

Essas variáveis serviram de base a um índice de importância das instituições democráticas, que soma as respostas recodificadas da pergunta sobre a possibilidade da democracia sem Congresso Nacional $^{7}$ e a da possibilidade da democracia sem partidos políticos (recodificada igual a anterior). O coeficiente de correlação entre estes itens é de gamma $=0,84$ e justifica a possibilidade da construção do índice.

Neste estudo também são usadas variáveis sobre a satisfação com a vida, opiniões sobre a economia e a situação política do país e sobre a situação econômica familiar. O objetivo, neste caso, é testar a validade da hipótese de que o indivíduo que é mais otimista confia mais nas instituições. Neste caso, as perguntas selecionadas são: "Como você classificaria em geral a situação econômica atual do

\footnotetext{
${ }^{7}$ A resposta "não pode haver democracia sem congresso" foi recodificada como 1 e a outra como zero.
} 
país?", "Como você classificaria em geral a situação econômica atual da sua família?" e "Como você classificaria em geral a situação política atual do país?"8.

A classificação da situação econômica atual do país, da situação econômica familiar, a visão sobre a situação política e a visão sobre o progresso do país são usadas para testar a hipótese de que um certo otimismo em relação à conjuntura se correlaciona positivamente com a confiança nas instituições políticas. Além disso, três perguntas com relação ao futuro foram combinadas gerando um índice de otimismo ${ }^{9}$.

\section{Análise dos Casos do Brasil, Argentina, Chile, Colômbia e Costa Rica}

Esta análise consiste em encontrar as variáveis que se correlacionam com a confiança nas instituições políticas, bem como as razões porque os cidadãos confiam mais ou menos tanto nas instituições quanto no sistema democrático de forma geral. As hipóteses principais deste estudo estão a seguir:

H1: A confiança nas instituições políticas aumenta com o apoio à democracia.

H2: A confiança nas instituições políticas é influenciada pela avaliação da performance governamental.

H3: A confiança nas instituições políticas aumenta com o otimismo.

H4: A confiança nas instituições políticas é influenciada pelo interesse e acompanhamento da política.

A primeira hipótese é a de que a confiança nas instituições políticas é influenciada positivamente pela adesão aos valores democráticos. Quanto maior o apoio ao sistema democrático, maior a confiança nas instituições políticas. O teste da relação entre a confiança política e as variáveis de apoio ao sistema democrático em separado e com o índice de importância das instituições democráticas (Tabela

\footnotetext{
${ }^{8}$ As respostas são: (1, muito boa; 2, boa; 3, regular; 4, ruim; 5, muito ruim); tendo estas duas últimas códigos iguais aos da primeira. Todas foram recodificadas em: 0, muito ruim, 4 ruim, 3 regular, 2 boa e 1 muito boa.

9 As perguntas são: "Como vê o ano que vem?" ; "Você diria que este país está progredindo, está estancado ou está em retrocesso?", e, "Como você vê sua situação econômica familiar futura?". Para efeito de construção do índice, esta última foi recodificada, atribuindo-se 1 ponto à resposta melhor e 0 às demais. Com isso obtivemos uma distribuição que variou entre 0 e 3 pontos, sendo esta em seguida recodificada em quatro categorias: pessimista (0), pouco otimista (1), otimista (2) e muito otimista (3). Coeficientes de correlação (gamma) entre os componentes do índice: situação econômica familiar futura e esperança $=0,59$; situação econômica familiar futura e progresso = 0,34 e esperança e progresso $=$ 0,51. (nível de significância de 0,01).
} 
6) mostrou que, com a exceção da Costa Rica, nos demais casos há relação estatística e correlação entre confiança nas instituições políticas e visões sobre a democracia. Os valores da correlação gamma indicam o número de pares de observações influenciados, porém, não nos indicam a direção da relação (Tabela 7). Para saber de que forma ocorre essa influência, analisamos as tabelas de cruzamentos entre confiança política e visões sobre a democracia.

\section{Tabela 6}

Índice de importância das Instituições Democráticas, por País (\%)

\begin{tabular}{|c|c|c|c|}
\hline & Pouca importância & Média & Muita importância \\
\hline Argentina & 11,9 & 18,1 & 70 \\
\hline Brasil & 31,1 & 27,1 & 41,9 \\
\hline Colômbia & 27,1 & 31,4 & 41,5 \\
\hline Costa Rica & 8,6 & 15,1 & 76,3 \\
\hline Chile & 17,9 & 20 & 62,2 \\
\hline
\end{tabular}

Fonte: Latinobarômetro 1996.

Tabela 7

Coeficientes de correlação (gamma) entre o Índice de confiança nas Instituições Políticas e valores democráticos, por País

\begin{tabular}{|c|c|c|c|c|}
\hline & $\begin{array}{c}\text { Preferência } \\
\text { pela } \\
\text { Democracia }\end{array}$ & $\begin{array}{c}\text { Possibilidade da } \\
\text { Dem. sem } \\
\text { Congresso Nacional }\end{array}$ & $\begin{array}{c}\text { Possibilidade da } \\
\text { Dem. sem } \\
\text { Partidos Políticos }\end{array}$ & $\begin{array}{c}\text { Índice de } \\
\text { Importância } \\
\text { das Inst. } \\
\text { Democráticas }\end{array}$ \\
\hline Argentina & $0,22^{*}$ & $0,38^{*}$ & $0,39^{*}$ & $0,35^{*}$ \\
\hline Brasil & $0,11^{*}$ & $0,36^{*}$ & $0,30^{*}$ & $0,31^{*}$ \\
\hline Colômbia & $0,13^{*}$ & $0,45^{*}$ & $0,37^{*}$ & $0,40^{*}$ \\
\hline Costa Rica & $-0,7$ & 0,11 & $-0,6$ & 0,06 \\
\hline Chile & $0,41^{*}$ & $0,51^{*}$ & $0,49^{*}$ & $0,48^{*}$ \\
\hline
\end{tabular}

* nível de significância 0,01

** nível de significância de 0,05

Fonte: Latinobarômetro 1996 
Há um leve aumento do percentual de confiança política entre os níveis mais altos de apoio à democracia, embora os níveis mais baixos pareçam estar onde se dá a maior influência. Assim, entre aqueles que apóiam um governo autoritário, a maioria tem confiança baixa ou muito baixa nas instituições políticas $(75,6 \%$ na Argentina, 63\% no Brasil, 58,2\% na Colômbia, 43,2\% na Costa Rica e 59,2\% no Chile).

O Gráfico 1 a seguir apresenta a distribuição daqueles que apóiam o regime autoritário no índice de confiança nas instituições políticas. Os dados mostram que à medida em que vai aumentando a confiança política, diminui o apoio a uma solução autoritária.

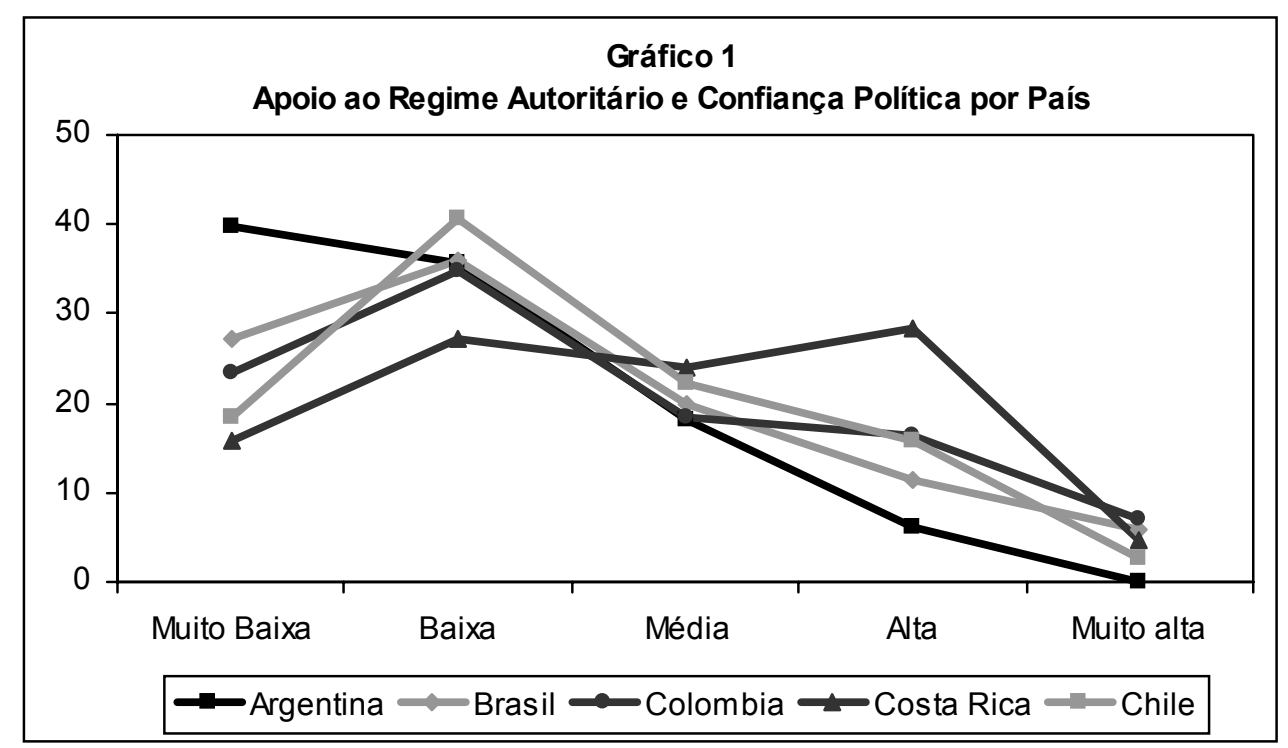

*Distribuição percentual daqueles que responderam "Em certas ocasiões é melhor um regime autoritário" à pergunta sobre preferência pela Democracia no índice de confiança nas instituições políticas.

O Gráfico 2 apresenta a distribuição daqueles que acham que a democracia pode funcionar sem partidos políticos segundo o índice de confiança, e indica que há um decréscimo desta visão com o aumento da confiança política. 


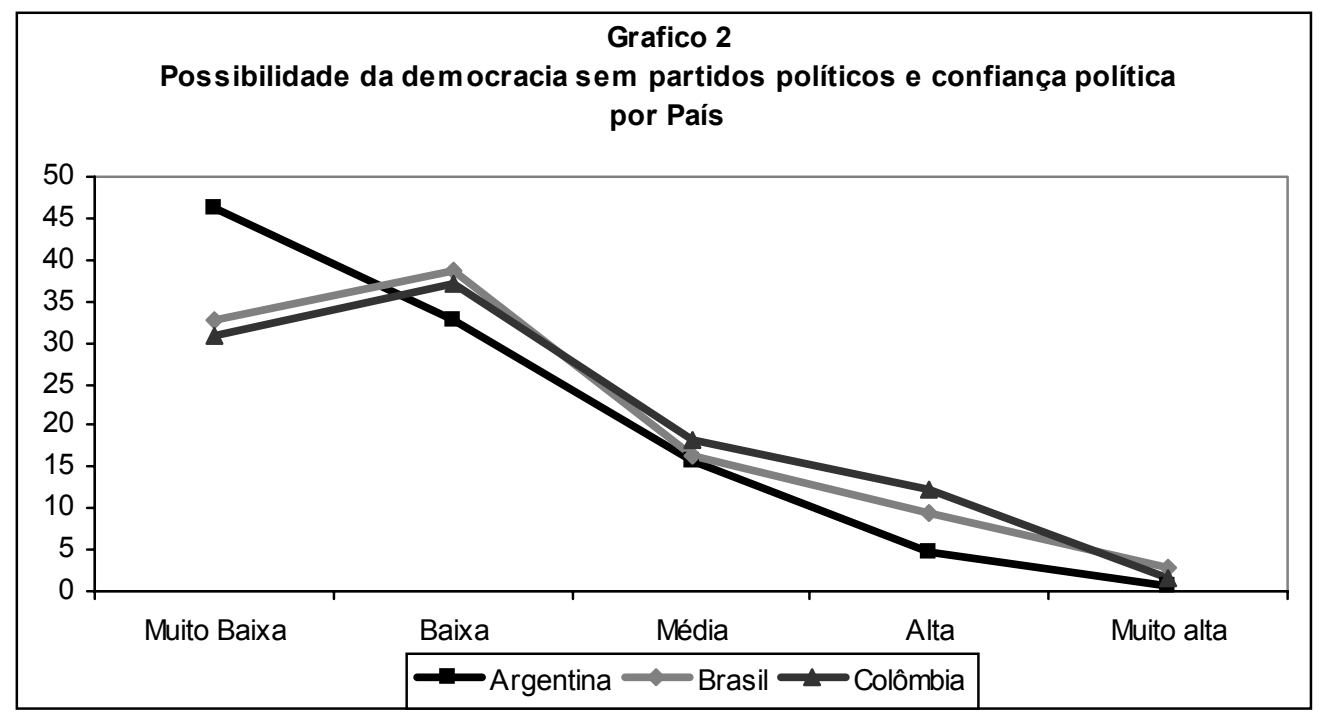

*Distribuição percentual daqueles que responderam que "A democracia pode funcionar sem partidos políticos" no índice de confiança política.

Por outro lado, se analisarmos a distribuição daqueles que preferem o sistema democrático entre o índice de confiança nas instituições políticas (Gráfico 3) veremos que, neste caso, o padrão não é tão explícito, sugerindo nuances que podem ser explicadas pela não existência de uma relação linear, ou por problemas de mensuração.

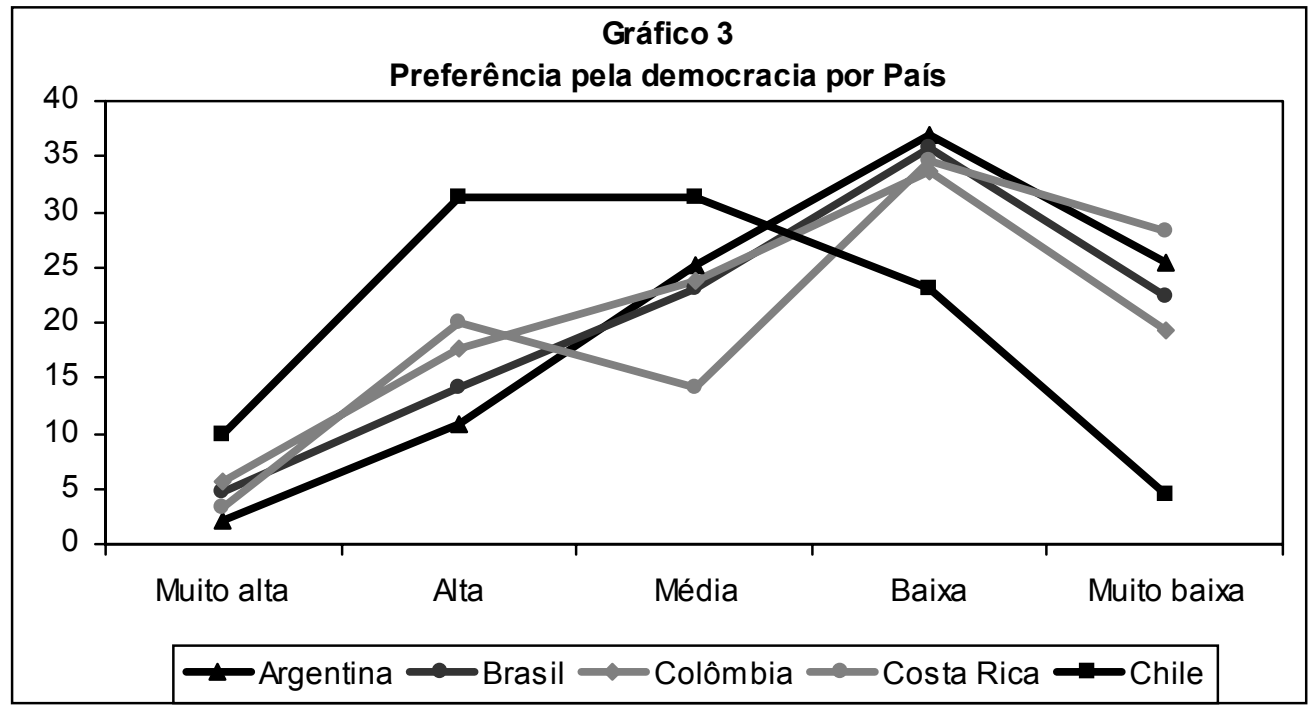

*Percentual de pessoas que preferem a democracia a qualquer outro regime distribuídas entre o índice de confiança nas instituições políticas. 
Embora não haja um padrão linear na relação entre apoio à democracia e confiança nas instituições políticas (o que impede de aceitar a hipótese de que a confiança política aumenta com o apoio à democracia) pode-se afirmar que, conforme aumenta a confiança política, diminui o apoio ao autoritarismo. Assim, cidadãos mais confiantes nas instituições da Presidência, Congresso e partidos têm maior tendência a serem contrários a um regime autoritário.

A literatura internacional sobre o decréscimo de confiança nas instituições políticas aponta a performance governamental como um dos fatores que têm levado à erosão da confiança. A incapacidade dos governos em atender às demandas sociais e o crescente descontentamento dos cidadãos são questões que fazem parte deste processo. Não há consenso sobre como mensurar a performance do governo (ORREN, 1999), porém, uma das maneiras de mensurá-la é através da avaliação que as pessoas fazem do governo e da economia do país.

Algumas das perguntas do Latinobarômetro podem ser consideradas de avaliação de diferentes aspectos do governo, ainda que não questionem de forma direta e geral a opinião que as pessoas têm sobre o governo, como em outros surveys. Usamos quatro variáveis para tentar mensurar a avaliação que as pessoas fazem da performance governamental, a saber, a satisfação com o funcionamento da democracia, a avaliação da situação econômica atual, a classificação da situação política atual e a classificação da situação econômica (as duas últimas se referem à estabilidade).

\section{Tabela 8}

\section{Coeficientes de correlação (gamma) entre o Índice de confiança nas Instituições Políticas e variáveis de avaliação governamental, por País}

\begin{tabular}{|c|c|c|c|c|}
\hline & $\begin{array}{c}\text { Satisfação com o } \\
\text { funcionamento da } \\
\text { Democracia }\end{array}$ & $\begin{array}{c}\text { Situação } \\
\text { econômica atual }\end{array}$ & $\begin{array}{c}\text { Classificação da } \\
\text { situação política }\end{array}$ & $\begin{array}{c}\text { Classificação } \\
\text { da situação } \\
\text { Econômica }\end{array}$ \\
\hline Argentina & $0,31^{*}$ & $0,30^{*}$ & $0,18^{*}$ & $0,23^{*}$ \\
\hline Brasil & $0,35^{*}$ & $0,19^{*}$ & $0,27^{*}$ & $0,31^{*}$ \\
\hline Colômbia & $0,26^{*}$ & $0,24^{*}$ & $0,25^{*}$ & $0,22^{*}$ \\
\hline Costa Rica & $0,08^{* *}$ & 0,04 & $0,23^{*}$ & $0,24^{*}$ \\
\hline Chile & $0,44^{*}$ & $0,36^{*}$ & $0,34^{*}$ & $0,38^{*}$ \\
\hline
\end{tabular}

* nível de significância 0,01

** nível de significância de 0,05

Fonte: Latinobarômetro 1996 
Os dados da Tabela 8 permitem confirmar que a avaliação realizada pelas pessoas sobre a situação político-econômica afeta o grau de confiança que elas possuem nas instituições políticas. Os cruzamentos de dados mostram que, dentre as pessoas que vêem a situação econômica atual do país como ruim ou péssima e as que são mais insatisfeitas com o funcionamento da democracia, os maiores percentuais são de "desconfiados" (Tabelas 8a e 8b, anexo).

O gráfico 4 mostra a distribuição da confiança nas instituições políticas entre aqueles que se afirmam muito insatisfeitos com o funcionamento da democracia.

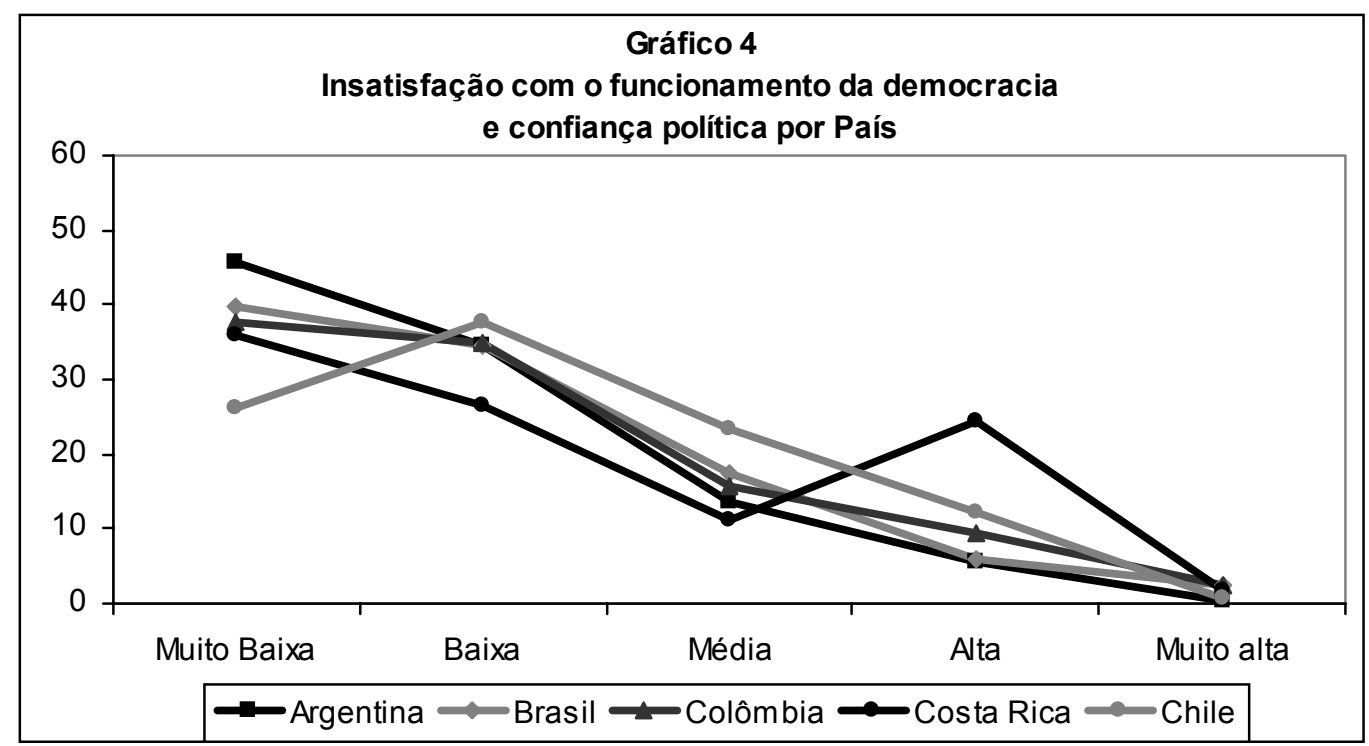

*Percentual de pessoas que estão nada satisfeitas com o funcionamento da democracia distribuídas entre o índice de confiança nas instituições políticas.

Se, no caso das visões negativas, caracterizada pela insatisfação com o funcionamento da democracia e avaliação da economia como péssima ou ruim, há uma tendência clara em observar um maior percentual de desconfiados politicamente, o contrário não se verifica no caso das visões positivas. Quando observamos a relação entre a boa avaliação da situação econômica e a confiança política, constatamos que não há um padrão regular, mas sim, influências, o que mostra ser necessário buscar aqui outras razões para a confiança. Os maiores percentuais tendem a se concentrar nos valores médios em quase todos os países. Assim, se para aqueles que têm uma visão ruim da economia podemos dizer mais claramente como se comportam em relação à confiança, para aqueles que têm uma 
avaliação boa da economia, outros fatores devem ser buscados para entender como se comportam no que concerne à confiança política.

Em trabalhos recentes sobre a erosão da confiança no governo e da confiança interpessoal (USLANER,1998; RENNÓ,1998), também foi lançada a hipótese de que cidadãos mais satisfeitos com a vida e mais otimistas teriam maior propensão a confiar tanto nas outras pessoas como nas instituições. Usamos algumas variáveis do Latinobarômetro na construção de um índice de otimismo para testar a hipótese de que o aumento do otimismo leva a um aumento da confiança.

Conforme mostra a Tabela 9, a maioria das correlações é positiva, ainda que não tão altas, indicando a existência de influência entre estas duas dimensões: otimismo e confiança. A correlação entre confiança interpessoal e confiança nas instituições políticas também é positiva e com valores moderados.

Tabela 9

\section{Coeficientes de correlação (gamma) entre o índice de confiança nas instituições políticas, satisfação com a vida e otimismo, por País}

\begin{tabular}{|c|c|c|c|c|c|c|c|}
\hline & $\begin{array}{c}\text { Satisfação } \\
\text { com a vida }\end{array}$ & $\begin{array}{c}\text { Confiança } \\
\text { Interpessoal }\end{array}$ & $\begin{array}{c}\text { Situação } \\
\text { econômica } \\
\text { familiar } \\
\text { atual }\end{array}$ & $\begin{array}{c}\text { Situação } \\
\text { econômica } \\
\text { familiar } \\
\text { futura }\end{array}$ & $\begin{array}{c}\text { Visão } \\
\text { sobre o } \\
\text { próximo } \\
\text { ano }\end{array}$ & $\begin{array}{c}\text { País está } \\
\text { progredindo }\end{array}$ & $\begin{array}{c}\text { Índice de } \\
\text { Otimismo }\end{array}$ \\
\hline Argentina & $0,07^{* *}$ & $0,16^{*}$ & $0,20^{*}$ & $0,20^{*}$ & $0,24^{*}$ & $0,36^{*}$ & $0,27^{*}$ \\
\hline Brasil & $0,18^{*}$ & $0,24^{* *}$ & 0,06 & $0,08^{* *}$ & $0,19^{*}$ & $0,28^{*}$ & $0,20^{*}$ \\
\hline Colômbia & $0,13^{*}$ & $0,16^{*}$ & $0,11^{*}$ & $0,10^{*}$ & $0,16^{*}$ & $0,18^{*}$ & $0,15^{*}$ \\
\hline Costa Rica & 0,02 & $0,14^{*}$ & $0,19^{*}$ & $0,08^{* *}$ & $0,19^{*}$ & 0,07 & $0,20^{*}$ \\
\hline Chile & $0,23^{*}$ & $0,18^{*}$ & $0,21^{*}$ & $0,14^{*}$ & $0,30^{*}$ & $0,35^{*}$ & $0,29^{*}$ \\
\hline
\end{tabular}

* nível de significância 0,01

** nível de significância de 0,05

Fonte: Latinobarômetro 1996

As correlações mais fortes neste grupo de variáveis estão entre a visão sobre o progresso do país e a confiança política. A variável "progresso" poderia também ser considerada uma variável de avaliação da performance do governo. Entretanto, optou-se por incluí-la neste índice dada sua relação com uma visão sobre o futuro ${ }^{10}$.

Por último, testamos a relação entre interesse, acompanhamento de notícias políticas e confiança política. As correlações entre interesse e confiança são altas e seguem o padrão esboçado na medida em que a influência se concentra nos

\footnotetext{
10 Ver distribuição das freqüências no Anexo, Tabelas 9a a 9f.
} 
patamares inferiores: pessoas que não se interessam por política e não acompanham notícias políticas tendem a ter menos confiança nas instituições ${ }^{11}$.

Tabela 10

Coeficientes de correlação (gamma) entre Interesse por política, Acompanhamento de Notícias Políticas e Confiança nas Instituições, por País

\begin{tabular}{|c|c|c|}
\hline & Interesse por Política & $\begin{array}{c}\text { Acompanhamento de notícias de } \\
\text { Política }\end{array}$ \\
\hline Argentina & $0,30^{*}$ & $0,24^{*}$ \\
\hline Brasil & $0,27^{*}$ & $0,18^{*}$ \\
\hline Colômbia & $0,30^{*}$ & $0,14^{*}$ \\
\hline Costa Rica & $0,23^{*}$ & $0,23^{*}$ \\
\hline Chile & $0,37^{*}$ & $0,34^{*}$ \\
\hline
\end{tabular}

* nível de significância 0,01

Fonte: Latinobarômetro 1996

Com relação às diferenças entre os países estudados ${ }^{12}$, alguns dados devem ser priorizados para pesquisas futuras. O Chile aparece como o caso onde há maior confiança política, sendo os índices de confiança na Presidência e no Congresso mais altos do que a confiança nos partidos políticos. No extremo oposto, Argentina e Brasil possuem as taxas mais baixas de confiança nas instituições políticas.

Com relação à influência da preferência pela democracia sobre a confiança, esta ocorre de maneira diferenciada. Na Costa Rica, as correlações não são estatisticamente significativas, indicando que, neste contexto, a democracia não é uma questão relevante para determinar a confiança. Nos demais países, entretanto, as correlações são estatisticamente significativas, sendo que o Chile se destaca pelas correlações mais altas $(0,41$ no caso de preferência pela democracia). 0 mesmo ocorre no caso das variáveis sobre performance governamental, uma vez que o Chile apresenta as correlações mais altas e a Costa Rica as mais baixas, o que leva a admitir a importância do contexto para a definição das causas da baixa confiança nestes países.

\footnotetext{
${ }^{11}$ Ver distribuição de freqüências no Anexo, Tabelas 10a e 10b.

12 Como dissemos, a metodologia de amostragem deste survey não é probabilística nacional, o que não permitiria fazer comparações mais amplas entre países com o devido rigor. Porém, objetiva-se aqui apenas apresentar as diferenças entre países encontradas neste estudo como indicadores para pesquisas futuras, seja na formulação de melhores instrumentos de análise ou de hipóteses alternativas para este fenômeno.
} 
Revendo as hipóteses iniciais deste trabalho pode-se afirmar que, em relação à influência dos valores democráticos sobre a confiança, fica claro que essa relação não é linear, como suposto. Entretanto, deve-se observar que no pólo negativo há uma influência, ou seja, o apoio ao autoritarismo diminui considerávelmente as chances de ocorrerem patamares altos de confiança política.

É conveniente ressaltar que os dados disponíveis permitiram pouca manipulação em relação à mensuração de valores democráticos. Neste sentido, um dos problemas emergentes desta análise é a ausência de outras variáveis que medissem indiretamente o apoio às normas democráticas, o que contribuiria, em princípio, para a formulação de um índice melhor. Além disso, a principal variável de análise - a preferência pela democracia - traz consigo um problema relativo à má formulação das respostas. A alternativa "tanto faz um regime democrático como um não-democrático" não é comparável em termos ordinais com as outras.

Ao testar a relação entre confiança nas instituições políticas e avaliação da performance governamental, confirma-se a hipótese de interligação entre estas duas dimensões. Além disso, avaliou-se a correlação entre algumas variáveis em separado com a confiança em vez de criar um índice de performance, pois não se possuíam os meios para tanto, ou seja, medidas objetivas de performance.

Destarte, considerou-se a performance governamental a partir da avaliação e classificação subjetiva da situação econômica, utilizando uma variável de avaliação da situação política. Foi relevante também avaliar a correlação entre confiança e satisfação com o funcionamento da democracia.

Por um lado, a avaliação da economia e a confiança estão relacionadas conforme o esperado; por outro, a força da correlação concentra-se no pólo negativo mais uma vez, ou seja, aqueles que têm uma visão de que a economia não está bem mostram, em maior número, uma confiança baixa ou muito baixa nas instituições. Com relação à satisfação com o funcionamento da democracia, as correlações também se mostraram moderadas e significativas em todos os países. A insatisfação com o funcionamento do regime aumenta as chances de baixa confiança.

Outra hipótese estudada neste trabalho foi a de que a confiança nas instituições políticas aumenta com o otimismo. Neste caso, optamos por construir um índice com variáveis que indicavam otimismo em relação à situação familiar futura e à situação do país. Como Rennó (1998, p.54) e Uslaner (1998) já haviam constatado em relação à confiança interpessoal, o otimismo também influencia a confiança política, o que indica a presença de um elemento que pode ser denominado de "propensão para confiar", que é subjacente aos diversos tipos de confiança e que depende, em certa medida, de disposições afetivas e psicológicas dos indivíduos. 


\section{Conclusão}

O estudo da confiança nas instituições políticas nos países da América Latina ainda tem muito que avançar. A relação que as pessoas têm com as instituições políticas é vital para entender a cultura política de desconfiança e aparências da região, como já identificaram Marta Lagos (2000) e Wanderley Guilherme dos Santos (1993).

Com o avanço dos surveys de atitudes e valores nos países da América Latina $^{13}$, pode-se dar prosseguimento a este estudo, identificando as relações entre o capital político e a confiança nas instituições políticas, bem como o papel do Estado na sua promoção.

Através das correlações encontradas, pode-se afirmar que a valorização da democracia, a visão sobre a economia e o funcionamento do regime, o otimismo em relação ao futuro e o interesse pela política influenciam a confiança nas instituições políticas. Além disso, dada a variação da confiança entre os países estudados e entre estes e os países trilaterais, pode-se afirmar que os contextos institucionais e históricos importam para o comportamento e a cultura política dos cidadãos. Da mesma forma, o contexto político e econômico é relevante para determinar a confiança, uma vez que interfere nas visões dos cidadãos sobre a economia, sobre o funcionamento das próprias instituições e pode mesmo minar ou gerar relações de confiança.

13 O ESEB (Estudo Eleitoral Brasileiro) realizado em 2002 pelo Datauff - Núcleo de Pesquisa e Informação da Universidade Federal Fluminense - e CESOP (UNICAMP) é uma das iniciativas neste sentido. 


\section{Bibliografia}

DALTON, R. \& WATTEMBERG, Martin P. (eds). Parties without Partisans. Political change in advanced industrial democracies. Oxford: Oxford University Press, 2000.

INGLEHART, R. The Renaissance of Political Culture. American Political Science Review. Vol 82, $\mathrm{n}^{\circ}$ 4, p. 1203-1229, 1988.

HUNTINGTON, S. P. In: PHARR, Susan J. Pharr \& PUTNAM, Robert (eds). Disaffected Democracies: What's Troubling The Trilateral Countries? Princeton: Princeton University Press, 2000.

LAGOS, Marta. A Máscara Sorridente da América Latina. Opinião Pública, vol. VI, nº 1, 2000.

MULLER, E. N. \& SELIGSON, M. A. Civic Culture and Democracy: The Question of Causal Relationships. American Political Science Review. vol 88, nº 3, p. 635-654, 1994.

ORREN, Gary. Fall from Grace: The Public's Loss of Faith in Government. In: NYE, Joseph; ZELIKOW , Philip \& KING, David (orgs.). Why People don't Trust Government. Londres: Harvard University Press, 1997.

PHARR, Susan J. Pharr \& PUTNAM, Robert (eds.). Disaffected Democracies: What's Troubling The Trilateral Countries?. Princeton: Princeton University Press, 2000.

PUTNAM, Robert D.; LEONARDI, Robert e NANETTI, Raffaella Y. Comunidade e Democracia: a experiência da Itália Moderna. Rio de Janeiro: Editora da Fundação Getúlio Vargas, 1996.

RENNÓ, Lúcio. Instituições, cultura política e lógica da desconfiança numa cidade brasileira. In: BAQUERO, Marcello (org). Desafios da Democratização na América Latina, 1998.

Confiança Interpessoal e Comportamento Político: microfundamentos da teoria do capital social na América Latina. Opinião Pública, vol. VII, número 1, 2001.

SANTOS, Wanderley Guilherme dos. Razões da Desordem. Ed. Rocco, RJ, 1993.

USLANER, E. M. Social Capital, Television and the Mean World: Trust, Optimism, and Civic participation. Political Psychology, vol. 19, n 3, 1998. 


\section{Anexo}

Tabela 1a

Confiança no Presidente da República, por País (\%)

\begin{tabular}{|c|c|c|c|c|}
\hline & Nenhuma & Pouca & Alguma & Muita \\
\hline Argentina & 46,5 & 28,7 & 18 & 6,8 \\
\hline Brasil & 25,1 & 39 & 21,9 & 14,1 \\
\hline Colômbia & 27,6 & 34,8 & 25,6 & 12 \\
\hline Costa Rica & 26,1 & 39,2 & 26 & 8,7 \\
\hline Chile & 10,5 & 28 & 40,7 & 20,8 \\
\hline
\end{tabular}

Fonte: Latinobarômetro 1996.

Tabela 1b

Confiança no Congresso Nacional, por País (\%)

\begin{tabular}{|c|c|c|c|c|}
\hline & Nenhuma & Pouca & Alguma & Muita \\
\hline Argentina & 29,3 & 36 & 28,8 & 5,8 \\
\hline Brasil & 29,7 & 42,2 & 18,6 & 9,5 \\
\hline Colômbia & 25,2 & 36,4 & 30,6 & 7,8 \\
\hline Costa Rica & 28,3 & 36,3 & 27,6 & 7,8 \\
\hline Chile & 11 & 34,4 & 41,9 & 12,7 \\
\hline
\end{tabular}

Fonte: Latinobarômetro 1996.

Tabela 1c

Confiança nos Partidos Políticos, por País (\%)

\begin{tabular}{|c|c|c|c|c|}
\hline & Nenhuma & Pouca & Alguma & Muita \\
\hline Argentina & 37 & 33,3 & 25,9 & 3,8 \\
\hline Brasil & 42,9 & 38,7 & 13,2 & 5,2 \\
\hline Colômbia & 35,9 & 34,7 & 23,5 & 5,9 \\
\hline Costa Rica & 37,1 & 35,8 & 23,8 & 3,2 \\
\hline Chile & 27 & 37,7 & 28,8 & 6,5 \\
\hline
\end{tabular}

Fonte: Latinobarômetro 1996.

Tabela 1d

Índice de confiança nas Instituições Políticas, por País (\%)

\begin{tabular}{|c|c|c|c|c|c|}
\hline & Muito baixa & Baixa & Média & Alta & Muito alta \\
\hline Argentina & 29,1 & 35,8 & 23,5 & 9,8 & 1,8 \\
\hline Brasil & 27,2 & 36,1 & 20,9 & 11,4 & 4,3 \\
\hline Colômbia & 22,3 & 34,1 & 21,7 & 16,5 & 5,4 \\
\hline Costa Rica & 28,4 & 33,5 & 15,1 & 19,8 & 3,1 \\
\hline Chile & 9,3 & 28,4 & 28,9 & 26,3 & 7 \\
\hline
\end{tabular}

Fonte: Latinobarômetro 1996. 
Tabela 8a

Classificação da situação econômica atual do país, por País (\%)

\begin{tabular}{|c|c|c|c|c|c|}
\hline & Muito ruim & Ruim & Regular & Boa & Muito boa \\
\hline Argentina & 24,3 & 39 & 30,3 & 6,2 &, 3 \\
\hline Brasil & 19,9 & 23,3 & 45,9 & 9,8 & 1,1 \\
\hline Colômbia & 18 & 31 & 44,5 & 5,9 &, 6 \\
\hline Costa Rica & 17,1 & 34 & 40,2 & 5,9 & 2,8 \\
\hline Chile & 4,7 & 26,1 & 51 & 17,6 &, 7 \\
\hline
\end{tabular}

Fonte: Latinobarômetro 1996.

Tabela 8b

Classificação da situação política, por País (\%)

\begin{tabular}{|c|c|c|c|c|}
\hline & Nada Estável & Algo Estável & Bastante Estável & Muito Estável \\
\hline Argentina & 29,2 & 43,9 & 20,7 & 6,3 \\
\hline Brasil & 32,4 & 35,4 & 25,4 & 6,9 \\
\hline Colômbia & 41,2 & 40,1 & 14,1 & 4,6 \\
\hline Costa Rica & 41,9 & 35,2 & 14,6 & 8,2 \\
\hline Chile & 19,2 & 44 & 31 & 5,7 \\
\hline
\end{tabular}

Fonte: Latinobarômetro 1996.

Tabela 9a

Satisfação com a vida, por País (\%)

\begin{tabular}{|c|c|c|c|c|}
\hline & $\begin{array}{c}\text { Não muito } \\
\text { satisfeito }\end{array}$ & Satisfeito & $\begin{array}{c}\text { Bastante } \\
\text { satisfeito }\end{array}$ & Muito satisfeito \\
\hline Argentina & 30,1 & 36,6 & 23,2 & 10 \\
\hline Brasil & 12,9 & 40,8 & 42,5 & 3,9 \\
\hline Colômbia & 15,4 & 39,9 & 23,9 & 20,8 \\
\hline Costa Rica & 13,7 & 28,3 & 23,1 & 34,9 \\
\hline Chile & 21,3 & 35,8 & 32,4 & 10,4 \\
\hline
\end{tabular}

Fonte: Latinobarômetro 1996.

Tabela 9b

Confiança Interpessoal, por País (\%)

\begin{tabular}{|c|c|c|}
\hline & Nunca se é suficientemente cuidadoso & $\begin{array}{c}\text { Pode-se confiar na maioria das } \\
\text { pessoas }\end{array}$ \\
\hline Argentina & 81,3 & 18,7 \\
\hline Brasil & 95,1 & 4,9 \\
\hline Colômbia & 72,8 & 27,2 \\
\hline Costa Rica & 69,6 & 30,4 \\
\hline Chile & 82 & 18 \\
\hline
\end{tabular}

Fonte: Latinobarômetro 1996. 
Tabela 9c

Classificação da situação econômica familiar atual, por País (\%)

\begin{tabular}{|c|c|c|c|c|c|}
\hline & Muito ruim & Ruim & Regular & Boa & Muito boa \\
\hline Argentina & 8,5 & 24,3 & 45,3 & 21,3 &, 7 \\
\hline Brasil & 4,5 & 13,6 & 57,1 & 21,9 & 2,9 \\
\hline Colômbia & 1,9 & 7,2 & 55,7 & 31,7 & 3,5 \\
\hline Costa Rica & 3,3 & 14,2 & 61 & 17,1 & 4,4 \\
\hline Chile & 2,2 & 14,8 & 56 & 26,1 &, 8 \\
\hline
\end{tabular}

Fonte: Latinobarômetro 1996.

Tabela 9d

Classificação da situação econômica familiar futura, por País (\%)

\begin{tabular}{|c|c|c|c|}
\hline & Pior & Igual & Melhor \\
\hline Argentina & 25,6 & 44,9 & 29,5 \\
\hline Brasil & 21,6 & 24,5 & 53,9 \\
\hline Colômbia & 14,4 & 31,7 & 53,9 \\
\hline Costa Rica & 24,4 & 51,4 & 24,1 \\
\hline Chile & 11,3 & 53,1 & 35,5 \\
\hline
\end{tabular}

Fonte: Latinobarômetro 1996.

Tabela 9e

Visão sobre o próximo ano, por País (\%)

\begin{tabular}{|c|c|c|}
\hline & Com Preocupação & Com Esperança \\
\hline Argentina & 47,4 & 52,6 \\
\hline Brasil & 32,4 & 67,7 \\
\hline Colômbia & 30,3 & 69,7 \\
\hline Costa Rica & 36,7 & 63,3 \\
\hline Chile & 40,1 & 59,9 \\
\hline
\end{tabular}

Fonte: Latinobarômetro 1996.

Tabela $9 f$

Visão sobre o progresso, por País (\%)

\begin{tabular}{|c|c|c|c|}
\hline & Está em retrocesso & Está estancado & Está progredindo \\
\hline Argentina & 27,7 & 51,8 & 20,5 \\
\hline Brasil & 21,8 & 46,8 & 31,4 \\
\hline Colômbia & 20,8 & 62,8 & 16,4 \\
\hline Costa Rica & 19,1 & 62,1 & 18,7 \\
\hline Chile & 11,6 & 44,4 & 44 \\
\hline
\end{tabular}

Fonte: Latinobarômetro 1996. 
Tabela 10a

Grau de interesse pela política, por País (\%)

\begin{tabular}{|c|c|c|c|c|}
\hline & Muito interessado & Algo interessado & $\begin{array}{c}\text { Pouco } \\
\text { interessado }\end{array}$ & Nada interessado \\
\hline Argentina & 9,8 & 20 & 24,8 & 45,4 \\
\hline Brasil & 5,6 & 18,8 & 40,6 & 34,9 \\
\hline Colômbia & 8,7 & 22,9 & 33,7 & 34,6 \\
\hline Costa Rica & 9,8 & 22,6 & 33,9 & 30,8 \\
\hline Chile & 5,4 & 22,3 & 32,1 & 40,3 \\
\hline
\end{tabular}

Fonte: Latinobarômetro 1996.

Tabela 10b

Acompanhamento de notícias de Política, por País (\%)

\begin{tabular}{|c|c|c|c|c|}
\hline & $\begin{array}{c}\text { Muito } \\
\text { frequentemente }\end{array}$ & Frequentemente & Quase nunca & Nunca \\
\hline Argentina & 12,5 & 36,2 & 34,8 & 16,5 \\
\hline Brasil & 7,2 & 31 & 35,3 & 26,4 \\
\hline Colômbia & 15,8 & 33,5 & 34,2 & 16,5 \\
\hline Costa Rica & 10 & 29,4 & 44,8 & 15,9 \\
\hline Chile & 8,6 & 31,8 & 26,4 & 33,1 \\
\hline
\end{tabular}

Fonte: Latinobarômetro 1996. 